\title{
A FUSION APPROACH FOR FLOOD MAPPING USING SENTINEL-1 AND SENTINEL-2 DATASETS
}

\author{
Beste Tavus ${ }^{1}$, Sultan Kocaman ${ }^{1, *}$, Hakan A. Nefeslioglu², Candan Gokceoglu ${ }^{2}$ \\ ${ }^{1}$ Dept. of Geomatics Engineering, Hacettepe University, 06800 Beytepe Ankara, Turkey - (beste.tavus, \\ sultankocaman)@ hacettepe.edu.tr \\ ${ }^{2}$ Dept. of Geological Engineering, Hacettepe University, 06800 Beytepe Ankara, Turkey - (hanefeslioglu, \\ cgokce)@ hacettepe.edu.tr
}

Commission III, WG III/6

KEY WORDS: Natural Hazards, Sentinel-1, Sentinel-2, Flood Mapping, Ordu (Turkey)

\begin{abstract}
:
The frequency of flood events has increased in recent years most probably due to the climate change. Flood mapping is thus essential for flood modelling, hazard and risk analyses and can be performed by using the data of optical and microwave satellite sensors. Although optical imagery-based flood analysis methods have been often used for the flood assessments before, during and after the event; they have the limitation of cloud coverage. With the increasing temporal availability and spatial resolution of SAR (Synthetic Aperture Radar) satellite sensors, they became popular in data provision for flood detection. On the other hand, their processing may require high level of expertise and visual interpretation of the data is also difficult. In this study, a fusion approach for Sentinel-1 SAR and Sentinel-2 optical data for flood extent mapping was applied for the flood event occurred on August $8^{\text {th }}, 2018$, in Ordu Province of Turkey. The features obtained from Sentinel-1 and Sentinel-2 processing results were fused in random forest supervised classifier. The results show that Sentinel-2 optical data ease the training sample selection for the flooded areas. In addition, the settlement areas can be extracted from the optical data better. However, the Sentinel-2 data suffer from clouds which prevent from mapping of the full flood extent, which can be carried out with the Sentinel-1 data. Different feature combinations were evaluated and the results were assessed visually. The results are provided in this paper.
\end{abstract}

\section{INTRODUCTION}

Flood events are one of the destructive and frequent disasters caused by heavy rainfall, snow melting, dam failure, lake or river overflows. The factors such as lack of proper infrastructure development, rapid urbanization, and insufficient consideration of environmental and climate conditions cause the flood hazard to be more destructive. Floods cause devastating consequences on the social, economic, and environmental structures. Because of the consequences of floods highly depend on the location, extent and depth of flooding, it is very important to know the surface properties and evaluate these properties together in the event of flood.

Earth observation (EO) data from space is used very useful in various stages of the flood management process by providing information without direct contact with the flood area during disaster. In this context, satellite optical and radar sensors are primary data providers for flood assessment and monitoring. Because of the different radiometric response of water surfaces, it is easier to identify flood from optical images than from SAR (Synthetic Aperture Radar) images (Ouled Sghaier et al., 2018). Techniques such as single-band thresholding, spectral water indices (Feyisa et al., 2014), segmentation and classification (Van der Sande et al., 2003; Ko et al., 2015) and fusion (Nandi et al.,2017) were applied for flood extraction from optical data. On the other hand, optical sensors are affected by the cloud cover, which limit their usability for this purpose. For this reason, they are employed for post-flood analysis mostly (Tong et al., 2018).
On the other hand, the increased temporal and spatial availability of SAR data has made it a valuable source of information for flood mapping. The fact that SAR systems penetrate the clouds and perform day and night acquisitions, provides important advantages in obtaining accurate information, especially in floods. For this reason, different methods have been used for flood mapping using SAR data in the literature such as visual interpretation (Oberstadler et al., 1997), histogram thresholding (Nakmuenwai et al.,2017; Tavus et al., 2018), supervised classification (Pulvirenti et al., 2013; Tavus et al., 2019), automatic segmentation (Pulvirenti et al., 2011), region growing (Matgen et al., 2011), change detection (Giustarini et al., 2013) and interferometric SAR coherence (Bazi et al., 2005).

For flood mapping, three combinations of remote sensing sensors are generally used in the literature, respectively applied to preduring and post-flood events. These are fusion of optical/optical sensors, SAR/optical sensors and SAR/SAR sensors. The second option is more advantageous considering the need for timely evaluation of flood events, which change their dynamics rapidly. Several methods were applied in the literature for flood mapping using multitemporal and multisource information recently (Tong et al., 2018; Zoka et al., 2018). However, further investigations are required for flood mapping by the fusion of optical and SAR datasets (Tong et al., 2018).

In this study, Sentinel-1 and Sentinel-2 images obtained under wet and dry weather conditions collected at near same time of flood event (i.e. August $10^{\text {th }}$ for Sentinel-1 and August $9^{\text {th }}$ for Sentinel-2) were employed for flood extent analysis. In this

\footnotetext{
* Corresponding author
} 
context, two different Sentinel-1 and two Sentinel-2 datasets were obtained from the Copernicus Open Access Hub of ESA (European Space Agency) and processed using the freely provided SNAP Tool by ESA.

Sentinel-1 is a C-band SAR satellite constellation operating at $\sim 5.7 \mathrm{~cm}$ wavelength and belongs to the Copernicus Program of ESA together with Sentinel-2. The constellation two satellites, i.e. Sentinel-1A and Sentinel-1B. Each satellite carries one two radar sensor and both operate at the same orbit. They were launched on April 3, 2014 (1A) and April 25, 2016 (1B), respectively (Plank, 2014). The temporal revisit time is 12 days for each, which results in 6 days for the combination (Nagler et al. 2016). 6 days is considered as a frequent revisit period.

The Sentinel-2 optical sensor takes images with ground sampling distance (GSD) ranging from $10 \mathrm{~m}$ to $60 \mathrm{~m}$ with the twin satellites, Sentinel-2A and Sentinel-2B. They were launched on June 23, 2015 (2A) and March 7, 2017 (2B), respectively (Sentinel, 2015). The number of bands in the sensors are 13, ranging from the visible, near infrared (NIR) and short wave infrared (SWIR) wavelengths with $290 \mathrm{~km}$ swath width and systematic five-day repeat observations globally (Gascon et al., 2017). Visible and NIR bands have $10 \mathrm{~m}$ GSD, Vegetation Red Edge and SWIR bands have 20m GSD and Coastal aerosol, Water vapour, and Cirrus bands have $60 \mathrm{~m}$ GSD (Drusch et al., 2012)

Initially, geometric and radiometric pre-processing of Sentinel-1 and Sentinel-2 datasets were needed in the study. The fusion approach applied here is at feature level. Therefore, after the preprocessing, derivations of Sentinel-2 visible and NIR bands were calculated. Regarding the SAR data, H-Alpha Dual Polarization method, a polarimetric decomposition method that supports flood analysis in urban areas, was applied. For this purposes of the study, multiple Sentinel-1 and Sentinel-2 datasets obtained from Copernicus Sentinel Scientific Data Hub (Copernicus, 2020). The processing was performed using the SNAP Tool provided by ESA. Finally, the random forest (RF) supervised classification technique was applied to both datasets for flood extent mapping.

The study is presented in four main sections. In Section 2, the study area and datasets analysed are described. The preprocessing steps and the flood extent mapping methodology applied to the Sentinel-1 and Sentinel-2 data are explained in detail in Section 3. Finally, Section 4 presents the results and discussions of the study and possible future developments.

\section{THE STUDY AREA AND THE DATA}

\subsection{The Study Site and the Flood Event}

The study area includes in Fatsa and Unye districts of Ordu Province, and Terme and Carsamba districts of Samsun Province. Both provinces are located in the northern part of Turkey, in the Black Sea Region. Figure 1 shows the location of the study area and the sub-areas used for the evaluation of the results.

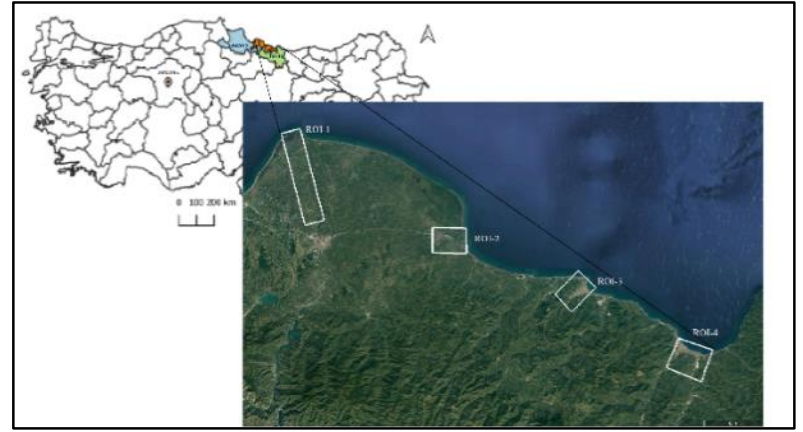

Figure 1. Location of the study area and sub-areas used for evaluation of the resulting flood map (study area coordinates: upper left: $36^{\circ} 35^{\prime} 13^{\prime \prime} \mathrm{E}, 41^{\circ} 25^{\prime} 01^{\prime \prime} \mathrm{N}$; lower right: $\left.37^{\circ} 36^{\prime} 11^{\prime \prime} \mathrm{E}, 40^{\circ} 47^{\prime} 45^{\prime \prime} \mathrm{N}\right)$.

The $60 \mathrm{~km}$ long coastal part of Ordu Province (out of $100 \mathrm{~km}$ ) consists of sandy beaches, which is a distinctive feature in the Black Sea Region (Demir et al., 2016). A typical wet Black Sea climate is dominant in Ordu. Almost all months of the year there is precipitation. In addition, there are 36 large and small rivers and streams in Ordu (Demir et al., 2016). In the province, the most common natural hazard is landslides $(80 \%)$, followed by floods $(9 \%)$ and rockfall $(8 \%)$ based on the data and statistics collected between 1950-2011 (Demir et al., 2016).

The flood event occurred in Ordu between 3-5 p.m. $(\mathrm{GMT}+3)$ in the afternoon on August 8, 2018. It caused damages to infrastructure and houses (Figure 2). In total, 8 bridges were destroyed and many landslides have occurred. About $80 \mathrm{~mm}$ of precipitation fell to the square meter on Fatsa and Unye Towns and caused stream and river floods. Cevizdere Bridge in Unye Town was demolished due to heavy rain, storm and flood and the Black Sea Coastal Highway was closed to traffic (TRT News, 2018).
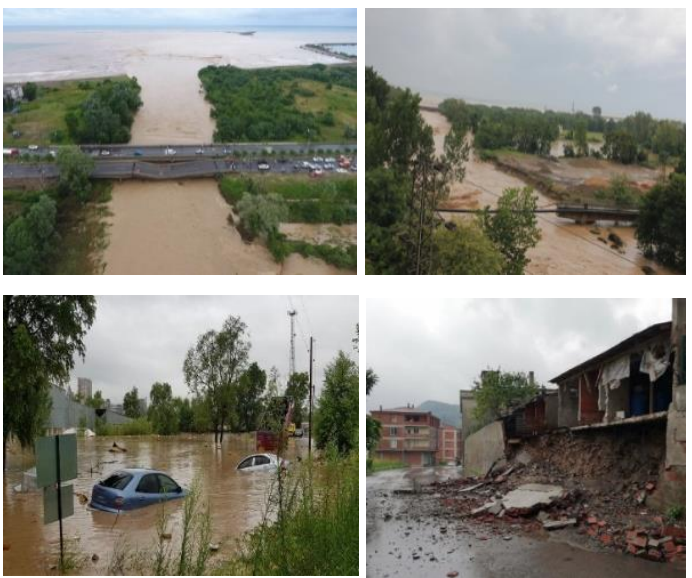

Figure 2. Examples to the damages after Aug $8^{\text {th }}, 2018$ flood in Ordu (photo credits: TRT News, 2018).

\subsection{Sentinel-1 and Sentinel-2 Datasets}

In total, 4 data-sets (DS) acquired with Sentinel-1 and 2 Sentinel 2 sensors were used in this study. The datasets were obtained under three different weather conditions during and after the flood (DS1, DS2, DS3), and one non-flood Sentinel-2 image (DS4) was also employed in the investigations. The Sentinel-1 SLC SAR and Sentinel-2 MSI Level 2A images provided by ESA 
used were obtained from ESA Copernicus Program (Copernicus, 2020).

In Table 1, the dataset specifications (i.e. imaging date, product type, and sensor mode, cloud conditions and the Uniform Resource ID) are provided. The DS1, DS2 are the most recent Sentinel-1 images available to the flood date, are acquired two days after the flood. Sentinel-1B images were acquired in interferometric wide (IW) swath mode and with dual polarization (VV and VH); while Sentinel-2 MSI images are obtained in product Level 2. Single Look Complex (SLC) data of Sentinel-1 has been used for in the polarimetric decomposition stage. While the Sentinel-2 image in DS3 in this study were used to select training fields and obtain some features of the flood areas, the DS4 image was used to produce the NDVI (normalized difference vegetation index) and MNDWI NDVI (modified normalized difference water index) information. The footprints of Sentinel-1 datasets (DS1 \& DS2) are shown in Figure 3. The two Sentinel-1 images covering the study area were combined in the pre-processing steps.

Table 1. Basic specifications of the Sentinel-1 and Sentinel-2 datasets used in the study.

\begin{tabular}{|c|c|c|c|c|}
\hline & ID & $\begin{array}{l}\text { Acquisiton } \\
\text { Date }\end{array}$ & $\begin{array}{l}\text { Data Type- } \\
\text { Mode }\end{array}$ & Conditions \\
\hline \multirow{2}{*}{ Sentinel-1 } & DS1 & 10 Aug 2018 & SLC-IW & Flooded \\
\hline & DS2 & 10 Aug 2018 & SLC-IW & Flooded \\
\hline \multirow{2}{*}{ Sentinel-2 } & DS3 & 9 Aug 2018 & Level-2A & Flooded \\
\hline & DS4 & 3 Oct 2018 & Level-2A & Non-Flooded \\
\hline \multicolumn{5}{|c|}{$\begin{array}{l}\text { ID and Uniform Resources Identifier (URI): } \\
\text { DS1:S1B_IW_SLC_1SDV_20180810T034028_20180810T034055_ } \\
\text { 012195_016770_AD16 }\end{array}$} \\
\hline \multicolumn{5}{|c|}{$\begin{array}{l}\text { DS2:S1B_IW_SLC__1SDV_20180810T034053_20180810T034120_ } \\
012195 \_016770 \_7035\end{array}$} \\
\hline \multicolumn{5}{|c|}{$\begin{array}{l}\text { DS3:S2B_MSIL2A_20180809T081559_N0208_R121_T37TCF_201 } \\
\text { 80809T132329 }\end{array}$} \\
\hline \multicolumn{5}{|c|}{$\begin{array}{l}\text { DS4:S2A_MSIL2A_20181003T081751_N0208_R121_T37TCF_201 } \\
\text { 81003T113110 }\end{array}$} \\
\hline
\end{tabular}

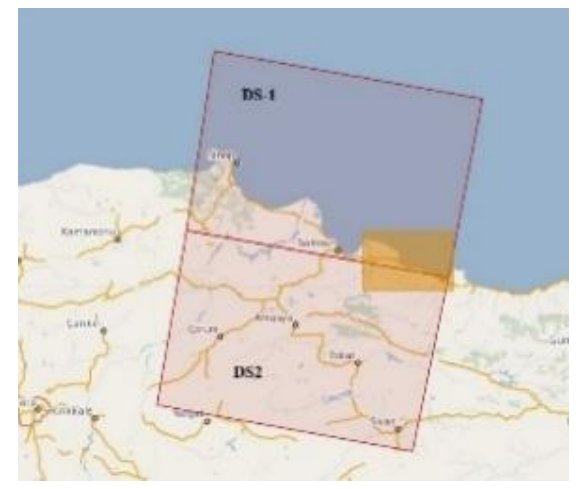

Figure 3. The footprints of and Sentinel-1 SLC scenes used in the study.

\section{METHODOLOGY}

SAR and optical data need to be corrected before information extraction due to some distortion that may occur during data collection. The pre-processing steps are explained in the following subsections for Sentinel-1 (Section 3.1) and Sentinel-
2 (Section 3.2). The pre-processed results have been combined into fusion dataset and the RF classifier was applied for predicting the classes. Finally, the classification results have been evaluated to detect the flooded areas. The overall workflow of the applied methodology is shown in Figure 4.

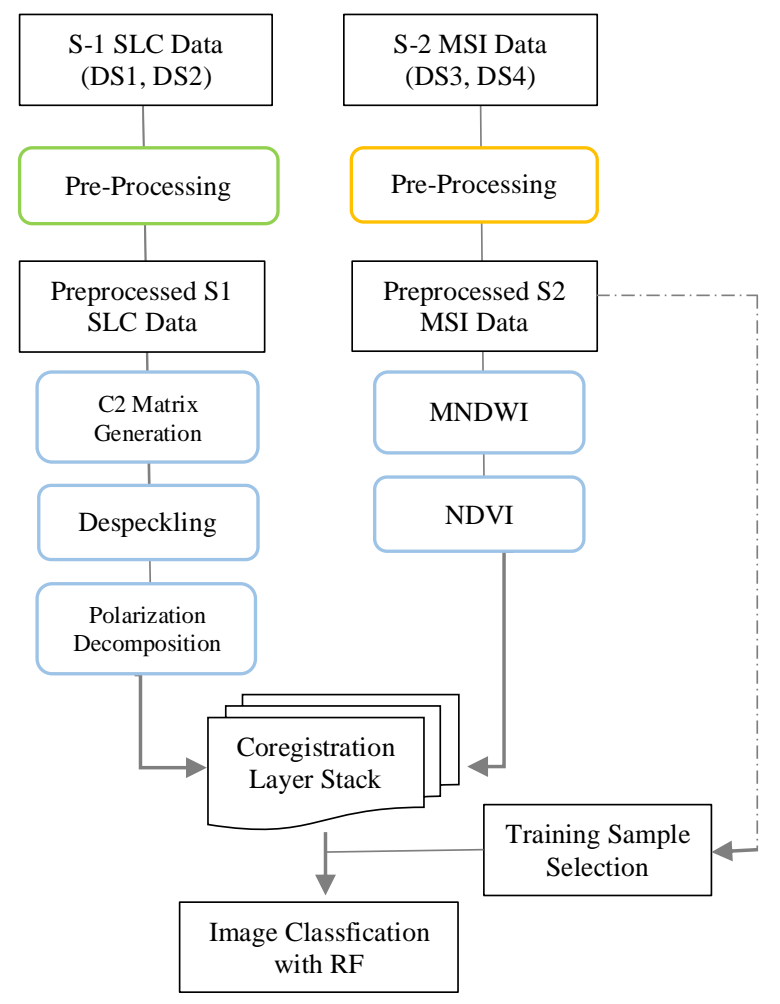

Figure 4. The methodological workflow of the flood extent mapping process.

\subsection{Processing of Sentinel-1 SLC Data}

The pre-processing steps applied to the Sentinel-1 images are shown in Figure 5. Sentinel-1 IW SLC products contain one image per sub-swath and one per polarisation channel; and each sub-swath image consists of a series of bursts (Minchella, 2016). For this reason, appropriate sub-swath and bursts were firstly selected from DS1 and DS2 data according to the selected study area boundaries using TOPSAR-Split from S1 SLC images consisting of three sub-swaths. Afterwards, using the S-1 Slice Assembly, splitted IW images were merged and precise orbit data was applied.

Radiometric calibration is essential for SAR image processing. This process is necessary for quantitative analysis of SAR data obtained from multiple sensors or at different times. This step allows representation of radar backscatter. The $\sigma_{0}$ bands were also created. In the deburst process, bursts in the selected subswaths were resampled to a common grid in range and azimuth by using TOPSAT-Deburst. 


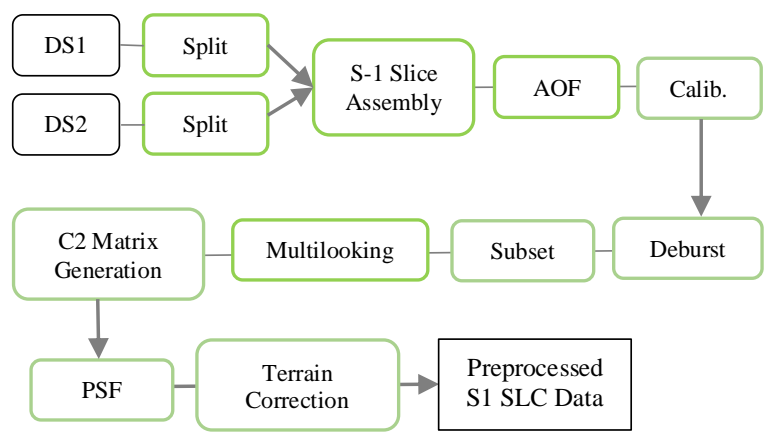

Figure 5. Preprocessing workflow of Sentinel-1 SLC products (AOF: Apply Orbit File, Calib: Radiometric Calibration, PSF: Polarimetric Speckle Filter).

For the polarimetric information extraction, $2 \times 2$ covariance matrix $\left(\mathrm{C}_{2}\right)$ has been applied to Sentinel-1 dual-pol (VV and $\left.\mathrm{VH}\right)$ data. Each element of the matrix represents information of targets that have a specific scattering mechanism in a particular polarization (Verma, 2012). The diagonal elements represent copol information; and the off-diagonal elements represent crosspol information. These matrix elements were processed for further investigation by despeckling with Improved Lee Sigma ( $7 \mathrm{x} 7$ window size) polarimetric speckle filters. Filtered $\mathrm{C} 11$ and C22 backscatter response in RGB combination obtained from the $\mathrm{C}_{2}$ matrix are given in Figure 6.

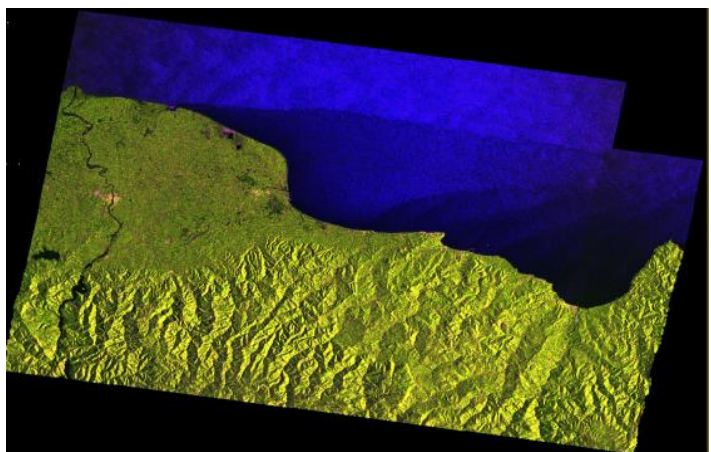

Figure 6. Filtered $\mathrm{C} 11$ and $\mathrm{C} 22$ backscatter response in RGB combination (red:C11, green: C22, blue: $\mathrm{C} 11 / \mathrm{C} 22$ ).

Finally, the image was terrain-corrected and orthorectified. The Range Doppler Terrain Correction algorithm was applied for this purpose. In addition, the Shuttle Radar Topography Mission (SRTM) with 1 arc-second spatial resolution and bilinear interpolation resampling technique were used for the geometric correction.

\subsection{Processing of Sentinel-2 MSI Data}

The DS3 Sentinel-2 image involves flood areas and were used to select training areas for classification. Due to the cloud effect present at the time of the flood, the cloud mask was applied to the DS3 image. The training areas were selected over true color combination (i.e. RGB) from the DS3 image. The processing workflow of Sentinel-2 MSI products is given in Figure 7.

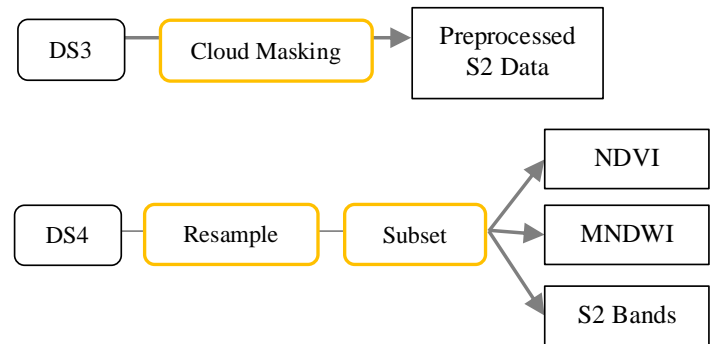

Figure 7. Preprocessing workflow of Sentinel-2 MSI products.

DS4 image was used in the production of NDVI and MNDWI bands. Since Band 3 (B3; $10 \mathrm{~m} \mathrm{GSD} ; 0.560 \mathrm{~nm}$ ), Band 4 (B4; 10 $\mathrm{m}$ GSD; $0.665 \mathrm{~nm}$ ), Band 8 (B8; $10 \mathrm{~m}$ GSD; $0.842 \mathrm{~nm}$ ) and Band 11 (B11; $20 \mathrm{~m} \mathrm{GSD} ; 1.610 \mu \mathrm{m})$ data were employed in the production of these indices, B11 with the lower resolution was first resampled to $10 \mathrm{~m}$. Pre-processed DS4 Sentinel-2 MSI image in true colour combination is given in Figure 8.

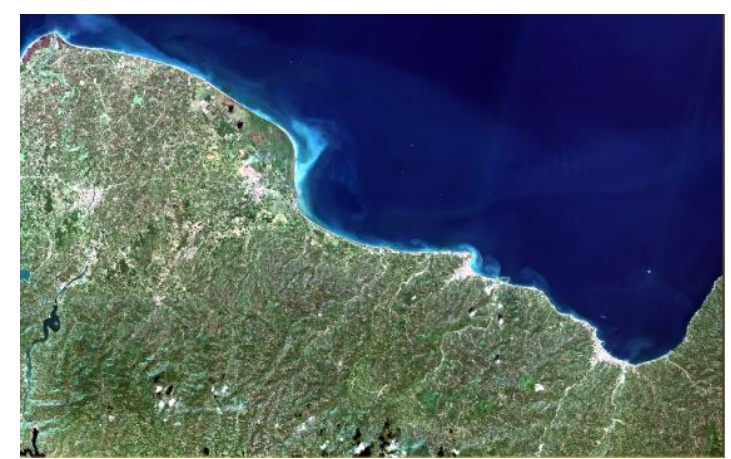

Figure 8. Pre-processed DS4 Sentinel-2 MSI image in true colour combination.

The NDVI computation is performed according to the formula given in Equation (1). The NDVI image produced from the DS4 image is given in Figure 9 together with the histogram.

$$
N D V I=\frac{N I R-R e d}{N I R+R e d}
$$

Although NDWI is the best known water index using the green and NIR bands and is effective in most cases for identifying water pixels; it may yield overestimation of water classes in residential areas. The NIR band has been replaced with the SWIR band to separate the settlement areas and the method is called MNDWI (Xu et al., 2006). For this reason, MNDWI (Equation 2) was used in this study for DS4. The output MNDWI image and its histogram are provided in Figure 10.

$$
M N D W I=\frac{\text { Green }-S W I R}{\text { Green }+S W I R}
$$




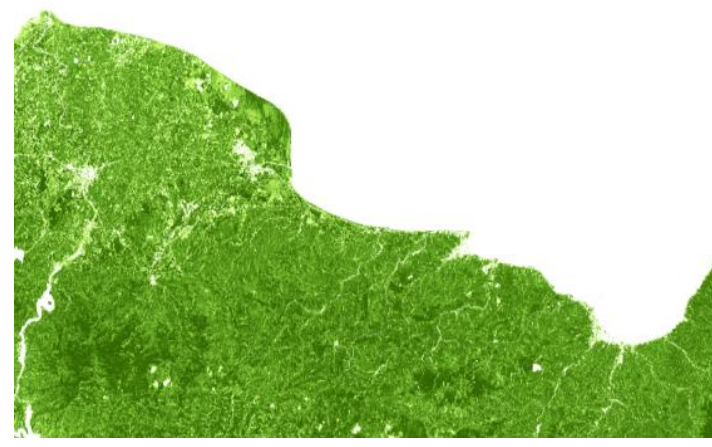

NDVI Histogram

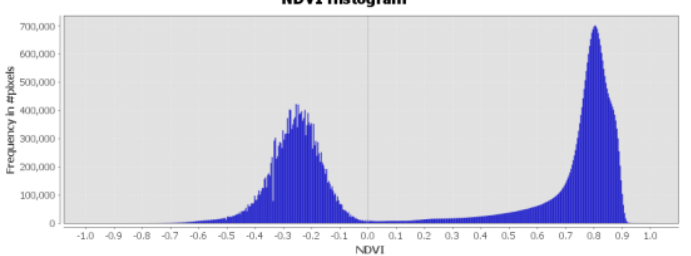

Figure 9. NDVI image (above) of DS4 and its histogram (below).

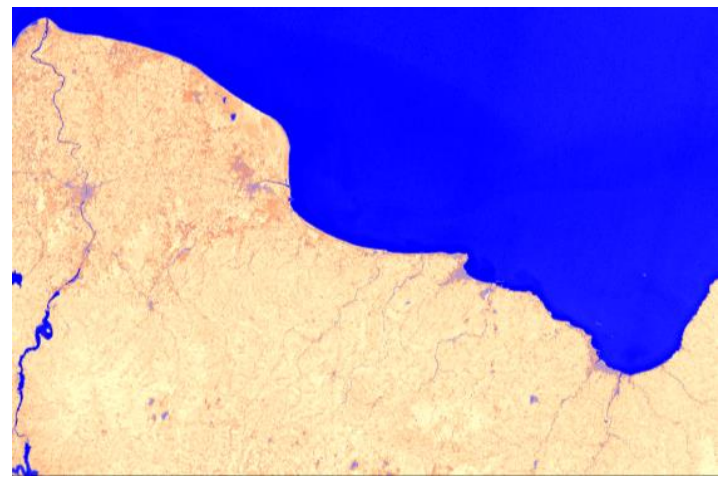

MNDWI Histogram

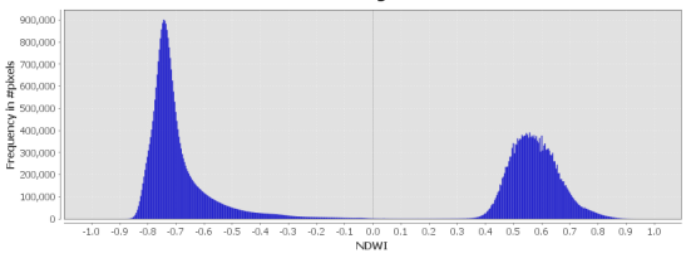

Figure 10. MNDWI image (above) of DS4 and its histogram (below).

\subsection{The Flood Extent Mapping Procedure}

Open water surfaces can easily be detected by using the low SAR backscatter information. In urban areas, the vegetation and floods areas exhibit very complex signal return due to multiple-bounce scattering. Based on the fact that more data can be extracted from dual or quad-pol data in comparison to single polarization; Polarimetric SAR (PolSAR) can be used for the purpose of separating flooded and non-flooded vegetation surfaces (Brisco et al. 2013; Plank et al., 2017). Polarimetric decomposition provide more information on the scattering contributions of objects. There are various polarimetric decomposition methods implemented in SNAP software, such Sinclair, Freeman-Durden, Yamaguchi, H- $\alpha$ Alpha etc.

Since the Sentinel-1 SLC images used in the study are dualpolarization, the entropy / anisotropy / alpha (H/A/ $\alpha)$ method was used for the polarimetric decomposition. This method relies on the eigenvalues and the eigenvectors of the coherency matrix (Cloude and Pottier 1997). The angle $(\alpha)$ defines the backscatter type, while entropy $(\mathrm{H})$ defines the heterogeneity of the scattering. Anisotropy (A) allows obtaining more information on the second and third backscattering in the pixel (Plank et al., 2017). The $\alpha, \mathrm{H}$, A data and $\mathrm{H}$-Alpha plane Plot obtained using the Dual-pol H/ $\alpha$ decomposition method is given in Figure 11.

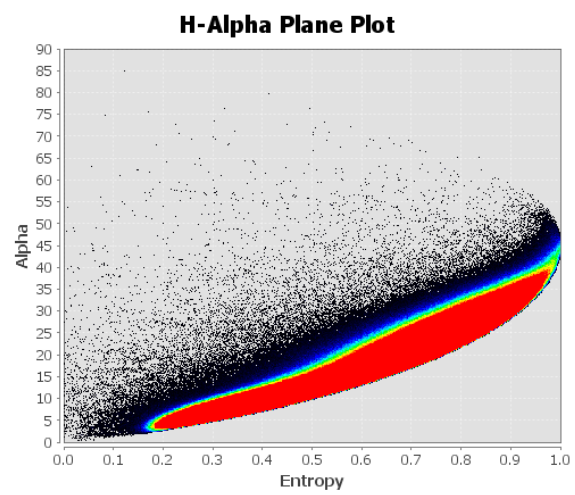

Figure 11. H-Alpha plane plot resulting from Dual-pol $\mathrm{H} / \alpha$ decomposition.

The images including the extracted feature data were coregistered to remove the geometric differences. Images were stacked together for the next step. Supervised classification is a common approach for information extraction from images and consists of two main stages: training and classification. During the training stage, a set of representative samples are selected for each class and in the classification stage, a classifier is used for the assessment of the probability of every image pixel to belong to the classes. In this study, the RF classification method implemented in the ESA SNAP Tool was applied for determining the flooded areas.

The RF classifier samples the data iteratively and randomly using the decision tree (DT) method. The results represent the statistical mode of many DT results and yields to a more robust model than a single DT (Breiman, 2001). The RF generally supply better classification results than for example the ML method (Balzter et al. 2015).

In this study, a land cover map with four classes including the flooded surfaces has been produced in SNAP software using the RF method. Different combinations of feature sets were also tested in a selected sub-area. Six classes were determined (permanent and flooded water surfaces, urban, forest, agriculture and bare land areas). The training areas (polygons) for each class were delineated from the preprocessed S2 data (DS3, flooded). The input layers employed in the model prediction stage include:

- Sentinel-1: C11 Intensity (VV), C22 Intensity (VH) layers

- $\quad$ Sentinel-2: All bands, NDVI, MNDWI layers

\section{RESULTS AND DISCUSSIONS}

Figure 12 shows the classification results of the whole area. The results obtained from the RF method were evaluated for the four sub-parts of the study area (Figure 13). After the initial visual investigations on the results, it was seen that the urban and bare soil areas could not be separated sufficiently, as well as the forest and agriculture areas. Therefore, these four classes were combined into two new classes as shown in Figure 13. 


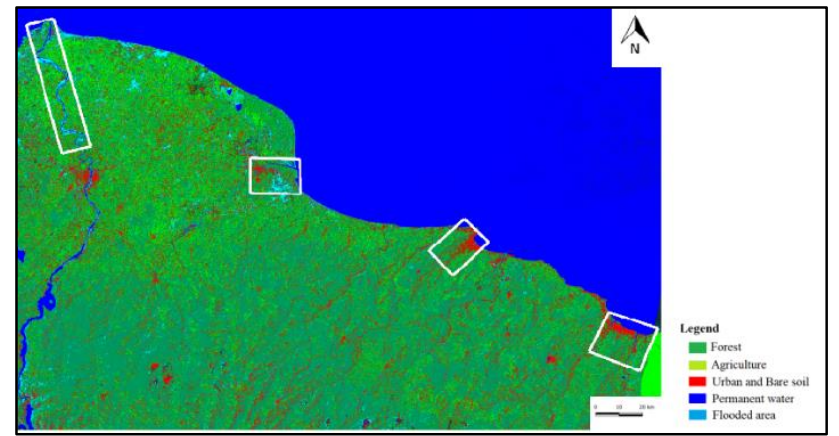

Figure 12. Result of the flood analysis produced for the whole study area.
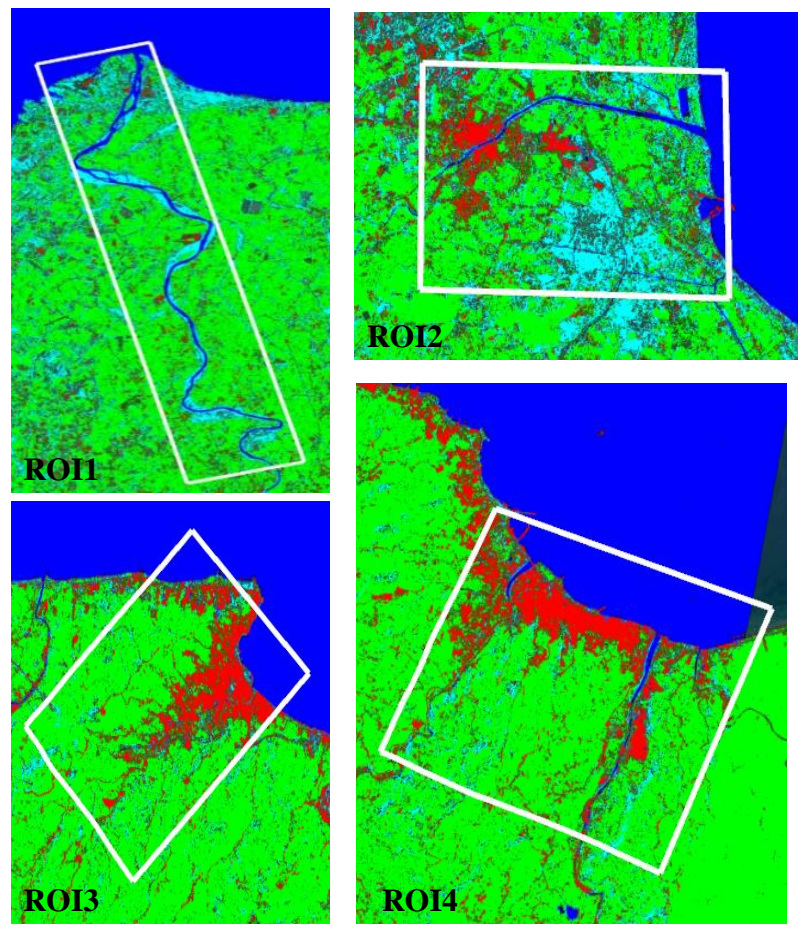

Forest-Agriculture Urban-Bare soil $\square$ Permanent water $\square$ Flooded area

Figure 13. Zoomed views of sub-areas.

In order to perform in-depth investigations, three different scenarios (combinations of input data layers and features) were applied for the Terme region (ROI-2 in Figure 13). The scenarios for the three tests are described in Table 2. The same training data, which exist in the selected region, were used for all three classifications. The classification results are presented in Figure 14 together with the Sentinel-2 RGB image (non-flooded condition) for visual assessment of the results. The results show that fusing the datasets yield the most accurate classifications. In ROI-1 remnant parts of oxbow lakes and back swamp areas and in ROI-2 lowland agricultural fields were obtained as flooded areas.

Table 2. Scenarios applied for classification over ROI-2.

\begin{tabular}{|l|l|}
\hline Scenario & Band Combination \\
\hline I & C11 Intensity+C22 Intensity \\
\hline II & $\begin{array}{l}\text { C11 Intensity+ C22 Intensity+ NDVI+ } \\
\text { MNDWI }\end{array}$ \\
\hline III & $\begin{array}{l}\text { C11 Intensity+ C22 Intensity+ NDVI+ } \\
\text { MNDWI+Sentinel-2 bands }\end{array}$ \\
\hline
\end{tabular}
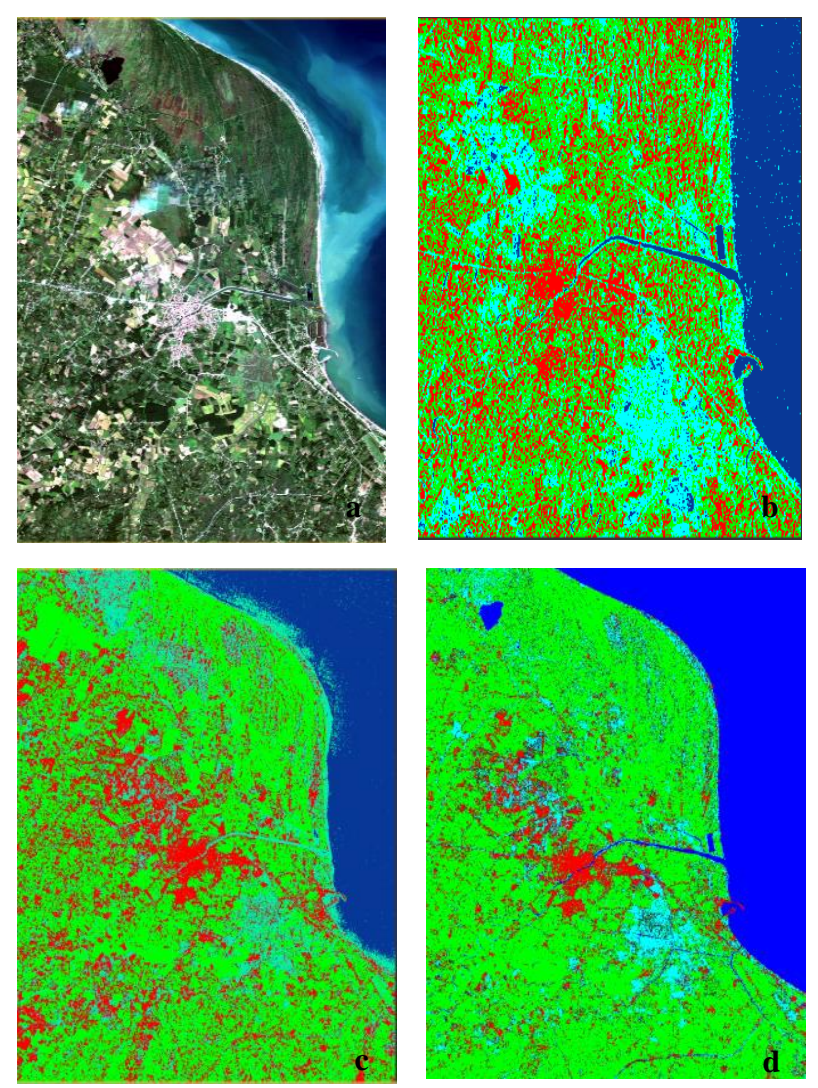

Figure 14. Results of flood analysis produced for the ROI-2 (a: Sentinel-2 MSI image in true colour combination, b: Scenario I classification result, c: Scenario II classification result, d Scenario III classification result).

\section{CONCLUSIONS AND FUTURE WORKS}

In this study, a feature level data fusion methodology was proposed for flood extent mapping using Sentinel-1 SAR and Sentinel-2 optical imagery. The random forest method was applied for land cover classification including permanent and flood water surfaces, forest, agricultural and urban areas and bare soil areas. The training data required by the supervised classification method were delineated manually on the optical dataset.

The results show that the flooded areas can be mapped with the proposed method. The freely available Sentinel-1 SAR and Sentinel-2 optical datasets and the SNAP Tool of ESA provide the sufficient means for this purpose, although application of the processing algorithm requires some level of expertise. The planned future works include ground data sampling and field investigations.

\section{REFERENCES}

Balzter, H., Cole, B., Thiel, C., and Schmullius, C., 2015. Mapping CORINE Land Cover from Sentinel-1A SAR and SRTM Digital Elevation Model Data using Random Forests. Remote Sensing, 7(11), 14876-14898.

Bazi, Y., Bruzzone, L., Melgani, F., 2005. An unsupervised approach based on the generalized Gaussian model to automatic change detection in multitemporal SAR images. IEEE 
Transactions on Geoscience and Remote Sensing, 43 (4), 874 887.

Breiman, L., 2001: Random forests. Machine Learning. Springer, 45(1), 5-32.

Brisco, B., A., Schmitt, K., Murnaghan, S., Kaya., A. Roth., 2013. SAR Polarimetric Change Detection for Flooded Vegetation. International Journal of Digital Earth, 6(2), 103114.

Cloude, S. R., Pottier, E., 1997. An Entropy Based Classification Scheme for Land Applications of Polarimetric SAR. IEEE Transactions on Geoscience and Remote Sensing, 35(1), 68-78.

Copernicus, 2020. Copernicus Open Access Hub. https://scihub.copernicus.eu/dhus/\#/home (3 May 2020).

Drusch, M., Del Bello, U., Carlier, S., Colin, O., Fernandez,V., Gascon, F., Hoersch, B., Isola, C., Laberinti P., Martimort, P., Meygret, A., Spoto, F., Marchese, F., Bargellini, P., 2012. Sentinel-2: ESA's optical high-resolution mission for GMES operational services. Remote Sensing of Environment, 120, 25 36.

Demir, A., Ilgen, H.G., Isik, A., 2016. Ordu İlinde, 0406/07/2016 Tarihleri Arasinda Meydana Gelen Sel-Taşkin-Su Baskini Ve Heyelan Olaylarinin Genel Değerlendirmesi. Presentation at 4. Ulusal Taşkın Sempozyumu, 21-24 Kasım, Rize, Turkey. http://www.dsi.gov.tr/docs/sempozyumlar/9ordu'da-meydana-gelen-sel-ta\%C5\%9Fk\%C4\% B1n-subask\%C4\%B1n\%C4\%B1-ve-heyelan-

olaylar\%C4\%B1n\%C4\%B1n-genel de\%C4\%9Ferlendirmesi-(ademir)DA0BB13A261E.pdf?sfvrsn=2 (3 May 2020).

ESA Scientific Data Hub-Copernicus, 2018. Available online: https://www.scihub.copernicus.eu/dhus/\#/home/ (1 September 2018).

Feyisa, G.L., Meilby, H., Fensholt, R., Proud, S.R., 2014. Automated Water Extraction Index: A new technique for surface water mapping using Landsat imagery. Remote Sensing Environment, 140, 23-35.

Gascon, F., Bouzinac, C., Thépaut, O., Jung, M., Francesconi, B., Louis, J., Lonjou, V., Lafrance, B., Masser, S., Gaudel Vacaresse, A., Languille, F., Alhammoud, B., Viallefon, F., Pflug, B., Bieniarz, J., Clerc, S., Pessiot, L., Tremas, T., Cadau, E., De Bonis, R., , C., Martimort, P., Fernandez, V., 2017. Copernicus Sentinel-2A calibration and products validation status. Remote Sensing, 9(6), 584.

Giustarini, L., Hostache, R., Matgen, P., Schumann, G.J.P., Bates, P.D., Mason, D.C., 2013. A Change Detection Approach to Flood Mapping in Urban Areas Using TerraSAR-X. IEEE transactions on Geoscience and Remote Sensing, 51(4), 24172430 .

Ko, B.C., Kim, H.H., Nam, J.Y., 2015. Classification of potential water bodies using Landsat $8 \mathrm{OLI}$ and a combination of two boosted random forest classifiers. Sensors, 15 (6), 13763-13777.

Matgen, P., Hostache, R., Schumann, G., Pfister, L., Hoffmann, L., Savenije, H.H.G., 2011. Towards an automated SAR-based flood monitoring system: Lessons learned from two case studies. Physics and Chemistry of the Earth, Parts A/B/C, 36 (7-8), 241252.
Minchella, A. 2016. Sentinel-1 Overview, ESA SNAP- Sentinel1 Training Course.

Nagler, T., Rott, H., Ripper, E., Bippus, G., Hetzenecker, M., 2016: Advancements for snowmelt monitoring by means of sentinel-1 SAR. Remote Sensing, 8(4), 348.

Nakmuenwai, P., Yamazaki, F., Liu, W., 2017. Automated Extraction of Inundated Areas from Multi-Temporal DualPolarization RADARSAT-2 Images of the 2011 Central Thailand Flood. Remote Sensing, 9(1), 78.

Nandi, I., Srivastava, P.K., Shah, K., 2017. Floodplain Mapping through Support Vector Machine and Optical/Infrared Images from Landsat 8 OLI/TIRS Sensors: Case Study from Varanasi. Water Resources Management, 31(4), 1157-1171.

Oberstadler, R., Hönsch, H., Huth, D., 1997. Assessment of the mapping capabilities of ERS-1 SAR data for flood mapping: a case study in Germany. Hydrological Process, 11 (10), 14151425 .

Ouled Sghaier, M., Hammami, I., Foucher, S., Lepage, R., 2018. Flood extent mapping from time-series SAR images based on texture analysis and data fusion. Remote Sensing, 10(2), 237.

Plank, S., 2014. Rapid damage assessment by means of multitemporal SAR-A comprehensive review and outlook to Sentinel1. Remote Sensing, 6(6), 4870-4906, https://doi.org/10.3390/rs6064870.

Plank, S., Jüssi, M., Martinis, S., Twele, A., 2017. Mapping of flooded vegetation by means of polarimetric Sentinel-1 and ALOS-2/PALSAR-2 imagery. International Journal of Remote Sensing, 38(13), 3831-3850.

Pulvirenti, L., Chini, M., Pierdicca, N., Guerriero, L., Ferrazzoli, P., 2011. Flood monitoring using multi-temporal COSMOSkyMed data: Image segmentation and signature interpretation. Remote Sensing of Environment, 115 (4), 990-1002.

Pulvirenti, L., Pierdicca, N., Chini, M., Guerriero, L., 2013. Monitoring flood evolution in vegetated areas using COSMOSkyMed data: The Tuscany 2009 case study. IEEE Journal of Selected Topics in Applied Earth Observations and Remote Sensing. 6 (4), 1807-1816.

Sentinel, E., 2015. Delivers First Images. Available online: http://www.esa.int/Applications/Observing_the_Earth/Copernic us/Sentinel-2/Sentinel-2_delivers_first_images

SNAP, 2018. Sentinel Application Platform. http://step.esa.int/main/toolboxes/snap/ (1 September 2018).

Tavus, B., Kocaman, S., Gokceoglu, C., Nefeslioglu, H.A., 2018. Considerations on the Use of Sentinel-1 Data in Flood Mapping In Urban Areas: Ankara (Turkey) 2018 Floods. Int. Arch. Photogramm. Remote Sens. Spatial Inf. Sci., 42(5), 575-581. https://doi.org/10.5194/isprs-archives-XLII-5-575-2018

Tavus, B., Kocaman, S., Nefeslioglu, H.A., Gokceoglu, C., 2019. Flood Mapping Using Sentinel-1 SAR Data: A Case Study of Ordu 8 August 2018 Flood. Bi-annual Symposium of Turkish Society for Photogrammetry and Remote Sensing, April 25-27, Aksaray, Turkey. 
Tong, X., Luo, X., Liu, S., Xie, H., Chao, W., Liu, S., Jiang, Y., 2018. An approach for flood monitoring by the combined use of Landsat 8 optical imagery and COSMO-SkyMed radar imagery. ISPRS Journal of Photogrammetry and Remote Sensing, 136, 144-153.

TRT News, 2018. Ordu'da Sel Felaketi. Online news portal of Turkish Radio Television Agency on 8 August 2018. https://www.trthaber.com/haber/turkiye/orduda-sel-felaketi379211.html (3 May 2020).

Van der Sande, C.J., De Jong, S.M., De Roo, A. P. J., 2003. A segmentation and classification approach of IKONOS-2 imagery for land cover mapping to assist flood risk and flood damage assessment. International Journal of Applied Earth Observation and Geoinformation, 4(3), 217-229.

Verma, R., 2012. Polarimetric Decomposition Based on General Characterisation of Scattering From Urban Areas and Multiple Component Scattering Model. University of Twente Faculty of Geo-Information and Earth Observation (ITC).

Zoka, M., Psomiadis, E., Dercas, N., 2018. The complementary use of optical and SAR data in monitoring flood events and their effects. Multidisciplinary Digital Publishing Institute Proceedings, 2(11), 644

Xu, H.Q., 2006. Modification of normalised difference water index (NDWI) to enhance open water features in remotely sensed imagery. International journal of remote sensing, 27(14), 30253033. 